\title{
Synthesis of Five-Membered Cyclic Ethers by Reaction of 1,4-Diols with Dimethyl Carbonate
}

\author{
Fabio Aricò, ${ }^{[a]}$ Pietro Tundo, ${ }^{*[a]}$ Andrea Maranzana ${ }^{[b]}$ and Glauco Tonachini ${ }^{[b]}$
}

The reaction of 1,4-diols with dimethyl carbonate in the presence of a base led to selective and high-yielding syntheses of related five-membered cyclic ethers. This synthetic pathway has the potential for a wide range of applications. Distinctive cyclic ethers and industrially relevant compounds were synthesized in quantitative yield. The reaction mechanism for the cyclization was investigated. Notably, the chirality of the starting material was maintained. DFT calculations indicated that the formation of five-membered cyclic ethers was energetically the most favorable pathway. Typically, the selectivity exhibited by these systems could be rationalized on the basis of hard-soft acid-base theory. Such principles were applicable as far as computed energy barriers were concerned, but in practice cyclization reactions were shown to be entropically driven.

\section{Introduction}

Many natural and synthetic compounds incorporate tetrahydrofuran rings as structural subunits (i.e., forskolin ${ }^{[1]}$ and manoyl oxide derivatives) ${ }_{,}^{[2]}$ and have significant biological activity: polyether antibiotics, ${ }^{[3]}$ inostamycins, ${ }_{1}^{[4]}$ and isosorbide ${ }^{[5]}$ are characteristic examples. Additionally, some cyclic ethers have distinctive aromas and are useful as fragrances. An example is (-)-norlabdane oxide, a compound widely used for providing ambergris-type odors to perfumes because natural ambergris itself is no longer available for this purpose. ${ }^{[6]}$

Amongst the commonly used synthetic approaches for the formation of cyclic ethers (through cyclization and/or cycloaddition) many involve heavy metals ${ }^{[7]}$ or chlorine chemistry at different levels; for example, activated chlorine-based leaving groups or leaving groups created through the use of chlorine (e.g., tosylate through the chlorosulfonation of toluene, mesylate). ${ }^{[8]}$ Also, cyclization reactions are often conducted under acidic conditions; many patents report the synthesis of tetrahydrofuran starting from the corresponding 1,4-butanediol by acid-catalyzed cyclodehydration. ${ }^{[9,10]}$ However, under these conditions, common cyclodehydration reactions are not very effective when tertiary alcohols are involved due to a mixture of elimination and/or rearrangement products. Recent advances in the synthesis of substituted tetrahydrofuran rings have been achieved by using different approaches with alternative starting materials and novel catalysts: ${ }^{[11]}$ for instance, the reaction of 1,4- and 1,5-diols with cerium ammonium nitrate ${ }^{[12]}$ proved to be very effective under mild conditions, although its application is limited because it requires the presence of at least one tertiary alcohol in the starting diols.

Short-chain dialkyl carbonates such as dimethyl carbonate (DMC), produced nowadays by clean processes, ${ }^{[13]}$ are renowned for possessing properties of low toxicity and high biodegradability, which make them true green solvents and reagents. ${ }^{[14]}$ DMC has been widely used as an efficient eco-sustainable substitute of phosgene, methyl halides or methyl sulfate that are toxic and highly corrosive. ${ }^{[15]}$ In fact, dialkyl carbo- nates, and in particular DMC, have shown high selectivity with different monodentate and bidentate nucleophiles, and act as methylating and/or methoxycarbonylation agents. ${ }^{[16]}$ The reactivity of the two electrophilic centres of DMC can be selectively tuned, temperature being the key factor: at reflux temperature $\left(90^{\circ} \mathrm{C}\right) \mathrm{DMC}$ acts as a methoxycarbonylation agent through the $B_{A C} 2$ mechanism, whereas at higher temperatures $\left(>150^{\circ} \mathrm{C}\right)$ the methylation reaction occurs through the $\mathrm{B}_{\mathrm{Al}} 2$ mechanism. Both reactions produce as byproduct only methanol and eventually $\mathrm{CO}_{2} \cdot{ }^{[14-16]}$

We have recently reported the synthesis of industrially relevant five-membered cyclic ethers and $\mathrm{N}$-heterocyclic compounds by DMC chemistry under mild conditions. ${ }^{[17]}$ To the best of our knowledge only one other example of a synthesis of tetrahydrofuran derivatives by dialkyl carbonate chemistry has been reported. ${ }^{[18]}$ Herein, we present this novel synthetic approach to several five-membered heterocycles. In the case of cyclic compounds previously investigated, ${ }^{[17]}$ reaction conditions were optimized (i.e., lower temperature and reduced amount of DMC) and reaction yields improved. The mechanism of intramolecular cyclization was also investigated by ${ }^{1} \mathrm{H}$ NMR spectroscopy and reaction intermediates were isolated and fully characterized. Furthermore, energy barriers associated with cyclization and with all possible concurrent pathways were explored by DFT calculations.

\footnotetext{
[a] Dr. F. Aricò, Prof. P. Tundo

Ca' Foscari Università di Venezia

Dipartimento Scienze Ambientali, Informatica e Statistica

Dorsoduro 2137-30123, Venice (Italy)

Fax: (+39) 041-234-8620

E-mail:tundop@unive.it

[b] Dr. A. Maranzana, Prof. G. Tonachini

Università degli Studi di Torino

Dipartimento di Chimica

Corso Massimo D'Azeglio, 48, 10125 Torino (Italy)

Supporting information for this article is available on the WWW under http://dx.doi.org/10.1002/cssc.201100755.
} 


\section{Results and Discussion}

\section{Cyclic ethers from 1,4-diols by DMC chemistry}

In a first set of experiments 1,4-butanediol was reacted with an excess of DMC, used as solvent and reagent, in the presence of sodium methoxide at reflux (Table 1, entry 1). As expected, 1,4-di(methoxycarbonyloxy) butane was the main product observed, whereas THF formed only in low yield. However, when the reaction was conducted in acetonitrile with four equivalents of DMC, THF was identified as the main product (70\%) (Table 1, entry 2). Quantitative conversion of 1,4-butanediol into THF was achieved by increasing the amount of base (Table 1, entry 3).

It was not convenient to use the preparation of THF through cyclization of 1,4-diols with DMC under batch conditions as a model reaction because the target molecule was very vola-

\begin{tabular}{|c|c|c|c|c|c|}
\hline \multirow[t]{2}{*}{ Entry } & \multirow[t]{2}{*}{$\begin{array}{l}\text { DMC } \\
\text { [equiv] }\end{array}$} & \multirow[t]{2}{*}{$\begin{array}{l}\mathrm{NaOMe} \\
\text { [equiv] }\end{array}$} & \multirow{2}{*}{$\begin{array}{l}\text { Cyclic ether }^{[b]} \\
{[\%]} \\
\text { THF }\end{array}$} & \multicolumn{2}{|c|}{$\begin{array}{l}\text { Other products }{ }^{[b]} \\
{[\%]}\end{array}$} \\
\hline & & & & $M M C D^{[c]}$ & $\mathrm{DMCD}^{\text {[d] }}$ \\
\hline 1 & $20^{[\mathrm{e}]}$ & 1.5 & 12 & 0 & $88(75)^{[f]}$ \\
\hline 2 & 4 & 1.5 & $70(82)^{[\mathrm{g}]}$ & $11(0)^{[g]}$ & $19(17)^{[g]}$ \\
\hline 3 & 4 & 2 & 100 & 0 & 0 \\
\hline
\end{tabular}

[a] Reaction conditions: 1,4-butanediol $(2.0 \mathrm{~g})$ in $\mathrm{CH}_{3} \mathrm{CN}(30 \mathrm{~mL})$ at $60^{\circ} \mathrm{C}$, $4 \mathrm{~h}$. [b] Yield based on GC-MS analyses. [c] Monomethoxycarbonyl derivative. [d] Dimethoxycarbonyl derivative. [e] DMC used as solvent. [f] Yield of isolated product. [g] Yield after $8 \mathrm{~h}$ based on GC-MS analyses.

tile. However, we overcame this issue by performing the reaction in a continuous-flow apparatus. ${ }^{[19]}$

The cyclization of 1,4-butanediol is reliant on the versatility of DMC as reagent. ${ }^{[16]}$ Most probably, the cyclization mechanism observed herein comprises first the methoxycarbonylation of the 1,4-diol by a $\mathrm{B}_{\mathrm{Ac}} 2$ mechanism, followed by an intramolecular cyclization through a $\mathrm{B}_{\mathrm{Al}} 2$ mechanism, in which a methylcarbonate anion is released (Scheme 1).

The formation of mono- and dimethoxycarbonyl derivatives (MMCD and DMCD, respectively) of the starting diol is a thermodynamically controlled equilibrium reaction, whereas the intramolecular $\mathrm{B}_{\mathrm{Al}} 2$ cyclization is kinetically driven. This reaction mechanism ultimately leads to the formation of the cyclic compound in a quantitative yield. Notably, the direct conversion of the diol vent (4 equiv).

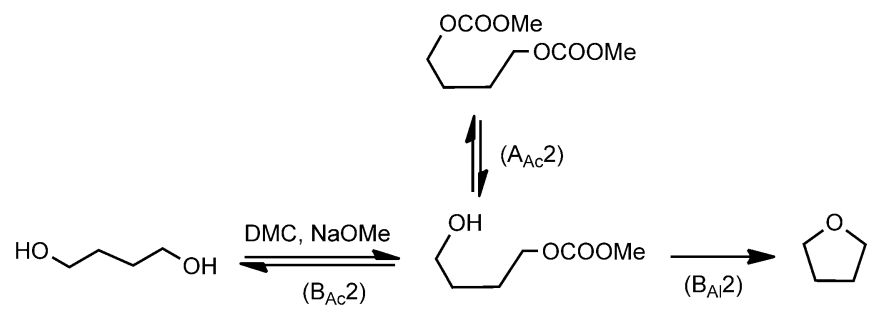

Scheme 1. Mechanism of cyclization of 1,4-diols.

into cyclic ethers by DMC chemistry has the advantage of being a single-step $S_{N} 2$ reaction, in which the leaving group is formed in situ. Conversely, $\mathrm{S}_{\mathrm{N}} 2$ reactions performed by commonly used chlorine chemistry require two steps: tosylation of the substrate followed by a $\mathrm{S}_{\mathrm{N}} 2$ reaction under basic conditions involving the purified tosyl derivative. Both steps cause the formation of large amounts of waste and require time-consuming purification of products.

A range of aliphatic and aromatic 1,4-diols, each bearing differently substituted alcohols (primary, secondary, tertiary, allyl, phenyl, and benzyl) were then investigated as substrates for the cyclization reaction. Table 2 contains results obtained for aliphatic diols. 1,4-Pentanediol formed 2-methyltetrahydrofuran in high yield under similar conditions to those used for 1,4-butanediol (Table 2, entry 3), whereas quantitative conversion required three equivalents of $\mathrm{NaOMe}$. This was possibly a result of the lower reactivity of secondary alcohols.

When 2,5-hexanediol (mixture of stereoisomers) was used, the cyclic ether formed in traces (14\%), and substrate conversion was moderate (52\%) even after $24 \mathrm{~h}$. Cyclization did not occur even with an excess of base (Table 2, entry 5). This result might be ascribed to secondary alcohols being less reactive both in the methoxycarbonylation $\operatorname{step}^{[14]}$ and in nucleophilic

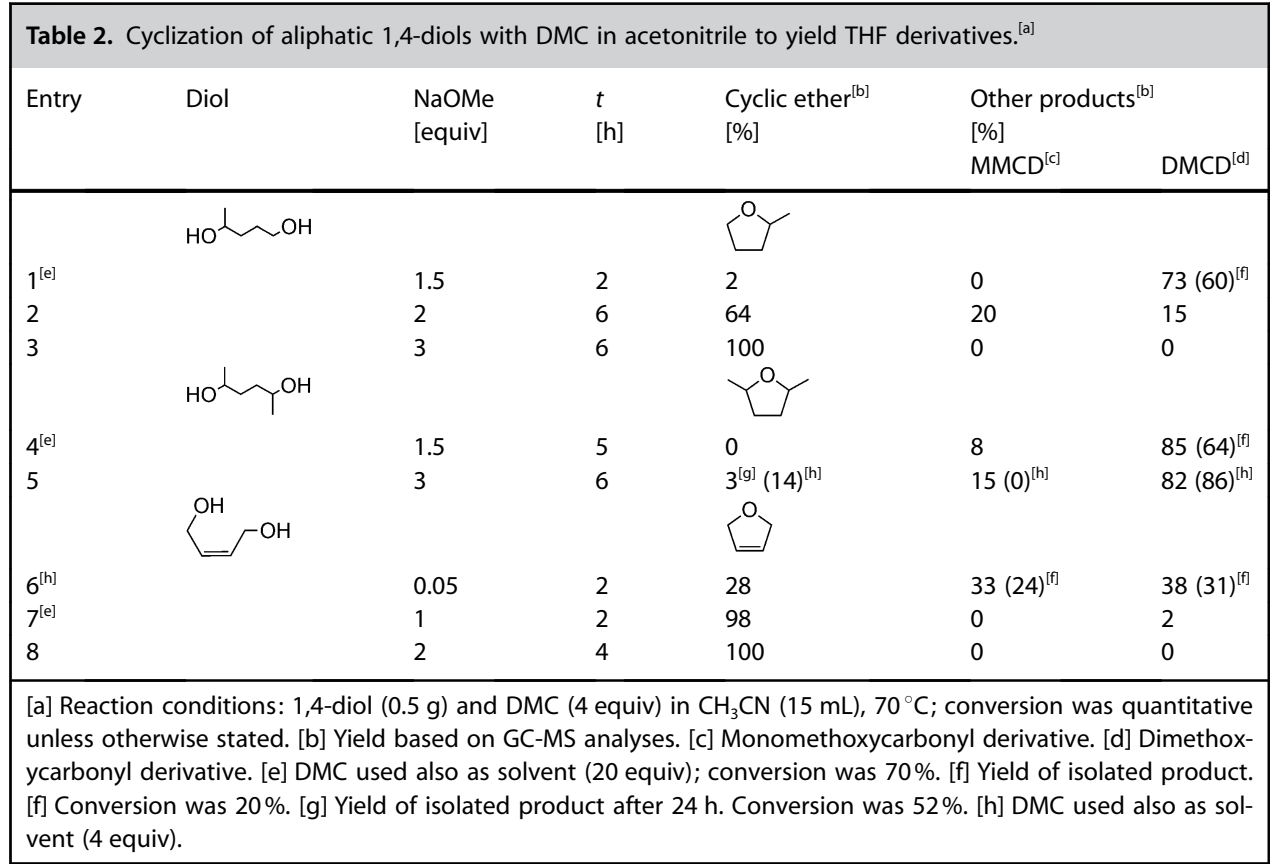

[a] Reaction conditions: 1,4-diol $(0.5 \mathrm{~g})$ and $\mathrm{DMC}$ (4 equiv) in $\mathrm{CH}_{3} \mathrm{CN}(15 \mathrm{~mL}), 70^{\circ} \mathrm{C}$; conversion was quantitative unless otherwise stated. [b] Yield based on GC-MS analyses. [c] Monomethoxycarbonyl derivative. [d] Dimethoxycarbonyl derivative. [e] DMC used also as solvent (20 equiv); conversion was $70 \%$. [f] Yield of isolated product. [f] Conversion was $20 \%$. [g] Yield of isolated product after $24 \mathrm{~h}$. Conversion was 52\%. [h] DMC used also as sol- 
substitution reactions. On the other hand, cis-1,4-but-2-ene diol underwent fast and quantitative cyclization (Table 2, entry 8), even with an excess of DMC (Table 2, entry 7). Most probably, the formation of 2,5dihydrofuran was aided by the favorable cis position of alcohol moieties; in fact, when the reaction was performed with a catalytic amount of base the cyclic compound still formed in appreciable yield (Table 2 , entry 6).

The cyclization of cis-1,4-but2-ene diol was also performed in deuterated acetonitrile to follow the formation of the cyclic ether by ${ }^{1} \mathrm{H}$ NMR spectroscopy (Figure 1): spectra showed that, after just $1 \mathrm{~h}$, the cyclic ether was the main product; small amounts of mono- and dimethoxycarbonyl derivatives, together with traces of the starting diol, were also present. After $4 \mathrm{~h}, 2,5$-dihydrofuran was the only product present in the solution.

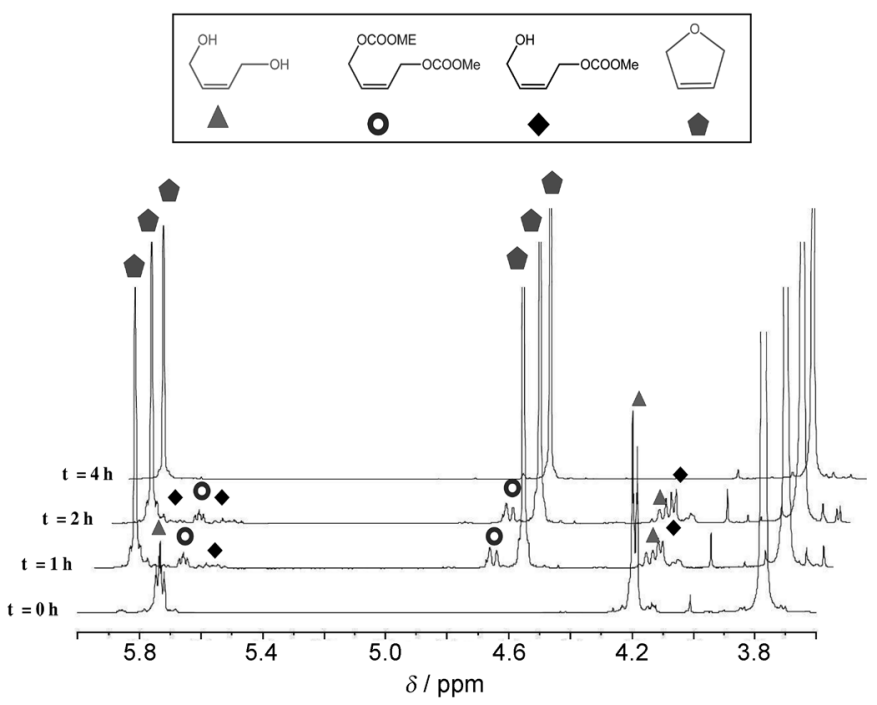

Figure 1. ${ }^{1} \mathrm{H}$ NMR spectra showing the formation of 2,5-dihydrofuran over time (under conditions in Table 2, entry 8).

The reactivity of 1,4-diols bearing aromatic moieties was also investigated (Table 3). 1,2-Dihydroxymethylbenzene and 2-(2hydroxyethyl)phenol were selected as substrates. 2-(2-Hydroxyethyl)phenol was one of the most reactive substrates because, even when utilizing catalytic amounts of base, 2,3-dihydrobenzofuran was the major product (Table 3, entry 1). Quantitative formation of the cyclic ether was achieved using two equivalents of base (Table 3, entry 2 and 3). The reaction was effective even with a small amount of DMC, and with acetonitrile as solvent (Table 3, entry 4). The cyclic compound was recovered after filtration of the base and evaporation of the sol- vent, and no further purification was required. In any case, the monomethoxycarbonyl derivative of the starting diol was the only intermediate observed.

1,2-Bis(hydroxymethyl)benzene also led to the quantitative formation of phthalan (Table 3, entry 7$)$ under reaction conditions similar to those used for 2-(2-hydroxyethyl)phenol. The dimethoxycarbonyl derivative of the starting 1,4-diol, the only intermediate formed, was isolated and characterized (Table 3, entry 5). Notably, the reaction solution was perfectly clear for all investigated substrates; this confirmed the absence of decomposition products (Table 1-3).

\section{Improving one-pot syntheses of ambroxan and isosorbide}

Norlabdane oxide (3) represents one of the preferred synthetic compounds with desirable ambergris-type odor and is commercially available under various trade names. ${ }^{[20,21]}$ Its industrial synthesis by cyclization of amberlyn diol under acidic condition leads to a mixture of ambroxan (ca. $60 \%$ ) and byproducts deriving from the concurrent elimination reaction. ${ }^{[21]}$

Table 4 includes results obtained by reacting amberlyn diol $^{[22]}$ (1) with DMC in the presence of a base. ${ }^{[17]}$ Results showed that using two equivalents of base in an excess of DMC (used as reagent and solvent), amberlyn diol cyclized quantitatively to ambroxan in only $3 \mathrm{~h}$ (Scheme 2 and Table 4, entry 1 ).

The amount of DMC could be reduced without affecting the outcome of cyclization (Table 4, entry 2 and 3). The cyclization was also performed using THF as solvent in the presence of three equivalents of DMC (Table 4, entry 4) without affecting the quantitative formation of ambroxan, whereas the chiral integrity of the starting material was maintained.

The mechanism of amberlyn diol cyclization most probably involved two steps: methylcarbonylation of the starting diol, followed by intramolecular nucleophilic attack by the tertiary alcohol. This hypothesis was confirmed by the fact that the monomethoxycarbonyl derivative was the only byproduct observed. This compound could be synthesized in quantitative 


\begin{tabular}{|lcccc|}
\hline \multicolumn{2}{|l|}{ Table 4. Synthesis of ambroxan by DMC chemistry. ${ }^{[a]}$} \\
Entry & Base & $\begin{array}{l}\text { DMC } \\
\text { [equiv] }\end{array}$ & $\begin{array}{l}\text { Ambroxan } \\
{[\%]}\end{array}$ & $\begin{array}{l}\text { MMCD } \\
{[\%]^{[b]}}\end{array}$ \\
\hline 1 & $t$ BuOK & 30 & 95 & 0 \\
2 & $t$ BuOK & 10 & 80 & 0 \\
3 & $t$ BuOK & 5 & 91 & 0 \\
$4^{[c]}$ & $t$ BuOK & 3 & 90 & 0 \\
5 & $\mathrm{~K}_{2} \mathrm{CO}_{3}$ & 30 & 0 & 90 \\
\hline
\end{tabular}
$3 \mathrm{~h}$; conversion of starting materials was $100 \%$. [b] Monomethoxycarbon- [a] Reaction conditions: amberlyn diol ( $1 \mathrm{~g}, 1$ equiv), base (2 equiv), $90^{\circ} \mathrm{C}$, yl derivative; [c] THF used as solvent.

\begin{tabular}{|c|c|c|c|c|c|}
\hline Entry & Solvent & $\begin{array}{l}\text { NaOMe } \\
\text { [equiv] }\end{array}$ & $\begin{array}{l}\text { DMC } \\
\text { [equiv] }\end{array}$ & $\begin{array}{l}t \\
{[\mathrm{~h}]}\end{array}$ & $\begin{array}{l}\text { Isosorbide } \\
\text { [b] }\end{array}$ \\
\hline 1 & None & 2 & 20 & 8 & 16 \\
\hline 2 & $\mathrm{MeOH}$ & 2 & 4 & 8 & $80(64)^{[c]}$ \\
\hline 3 & $\mathrm{MeOH}$ & 4 & 8 & 8 & $98(76)^{[c]}$ \\
\hline \multicolumn{6}{|c|}{$\begin{array}{l}\text { [a] Reaction conditions: D-sorbitol ( } 2 \mathrm{~g}, 1 \text { equiv) at reflux; conversion of } \\
\text { starting materials was } 100 \% \text {. [b] Yield based on GC-MS analyses. [c] Yield } \\
\text { of isolated product. }\end{array}$} \\
\hline
\end{tabular}

bide formed through a one-pot double cyclization requiring two equivalents of base for each cyclic ether formed.

\section{Ab initio calculations}

In all reactions DMC acts as an ambident elecrophile. First, one alcoholic functionality of the substrate reacts with the carbonyl group of DMC (hard-hard in-

yield using potassium carbonate as a base in the presence of an excess of DMC (Table 4, entry 5).

Cyclic ethers in the form of anhydro sugar alcohols have many applications in industry, particularly in food industry, in the pharmaceutical field, and they are also employed as monomers in the formation of polymers and copolymers. Such anhydro sugar alcohols are derivatives of mannitol, iditol, and sorbitol. Specifically, isosorbide, the anhydro sugar alcohol derived from sorbitol, is useful as a monomer in the manufacture of polymers and copolymers (especially polyesters). Isosorbide is industrially synthesized by dehydration of sorbitol by an acidcatalyzed reaction that leads to different anhydro compounds and polymer-like products. ${ }^{[23]}$

When D-sorbitol was reacted with two equivalents of base and an excess of DMC isosorbide was isolated in relatively low yields (Scheme 3 and Table 5, entry 1). This was because isosorbide, once formed, reacted with DMC and led to the formation of its methoxycarbonyl and methyl derivatives. ${ }^{[2]}$ However, when methanol was used as a solvent (Table 5, entry 2 and 3), the reaction equilibrium was shifted towards isosorbide preventing further reactions. Under these conditions, isosorbide formed readily and in high yield. The excess of $\mathrm{NaOMe}$ required (Table 5 , entry 3 ) was justified by the fact that isosor-
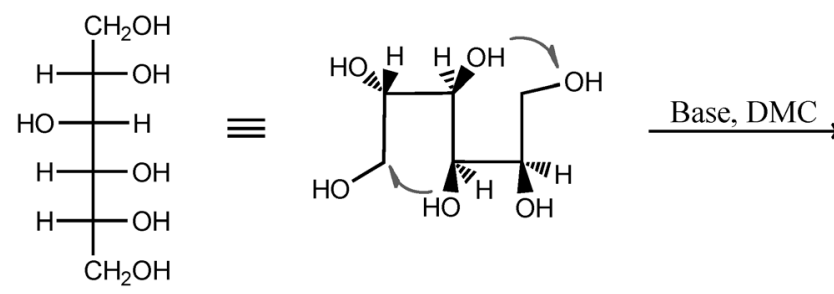

Scheme 3. Synthesis of isosorbide.

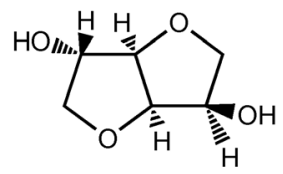

teraction ${ }^{[16]}$ forming the methoxycarbonyl derivative; the second alcoholic functionality then intramolecularly attacks the newly formed alkyl carbonate. According to the hard-soft acid-base (HSAB) theory of Pearson ${ }^{[25]}$ this should be a softsoft interaction. ${ }^{[17]}$ However, the results reported herein prove that this is not the case because the alcoholic moiety is a hard nucleophile. This discrepancy clearly indicates that the hard/ soft character of the nucleophile does not have a decisive influence on the reaction outcome. Thus, theoretical calculations are required to have a better insight in terms of energy barriers involved in the cyclization reaction. In this respect, we investigated four competing processes, namely two cyclization reactions and two bimolecular reactions involving DMC (Scheme 4). Free energies were assessed in the gas phase and in DMC solutions.

$(1 R, 2 S)$-2-(Hydroxyethyl)cyclohexanol (R) was selected as model molecule because it is incorporated as a subunit in amberlyn diol. $\mathrm{R}$ can undergo two competitive cyclizations to form either a five-membered ring through an intramolecular $\mathrm{S}_{\mathrm{N}}$ 2-like reaction (Scheme 4, pathway 1), or a seven-membered ring through an intramolecular $S_{N} A c$ reaction (Scheme 4, pathway 2). Furthermore, two intermolecular nucleophilic substitutions can also take place: an acylic one (Scheme 4, pathway 3, $\left.\mathrm{S}_{\mathrm{N}} A \mathrm{c}\right)$ and an aliphatic one (Scheme 4, pathway 4, $\mathrm{S}_{\mathrm{N}} 2$ ) due to the attack of alcoholate $\mathrm{R}$ on DMC.

Free energy data obtained in solution at $388 \mathrm{~K}\left(\Delta G_{\text {sol }}\right)$ demonstrated that methylation of the substrate leads to VI (Scheme 4, pathway 4), which is quite stable. However, the free energy 


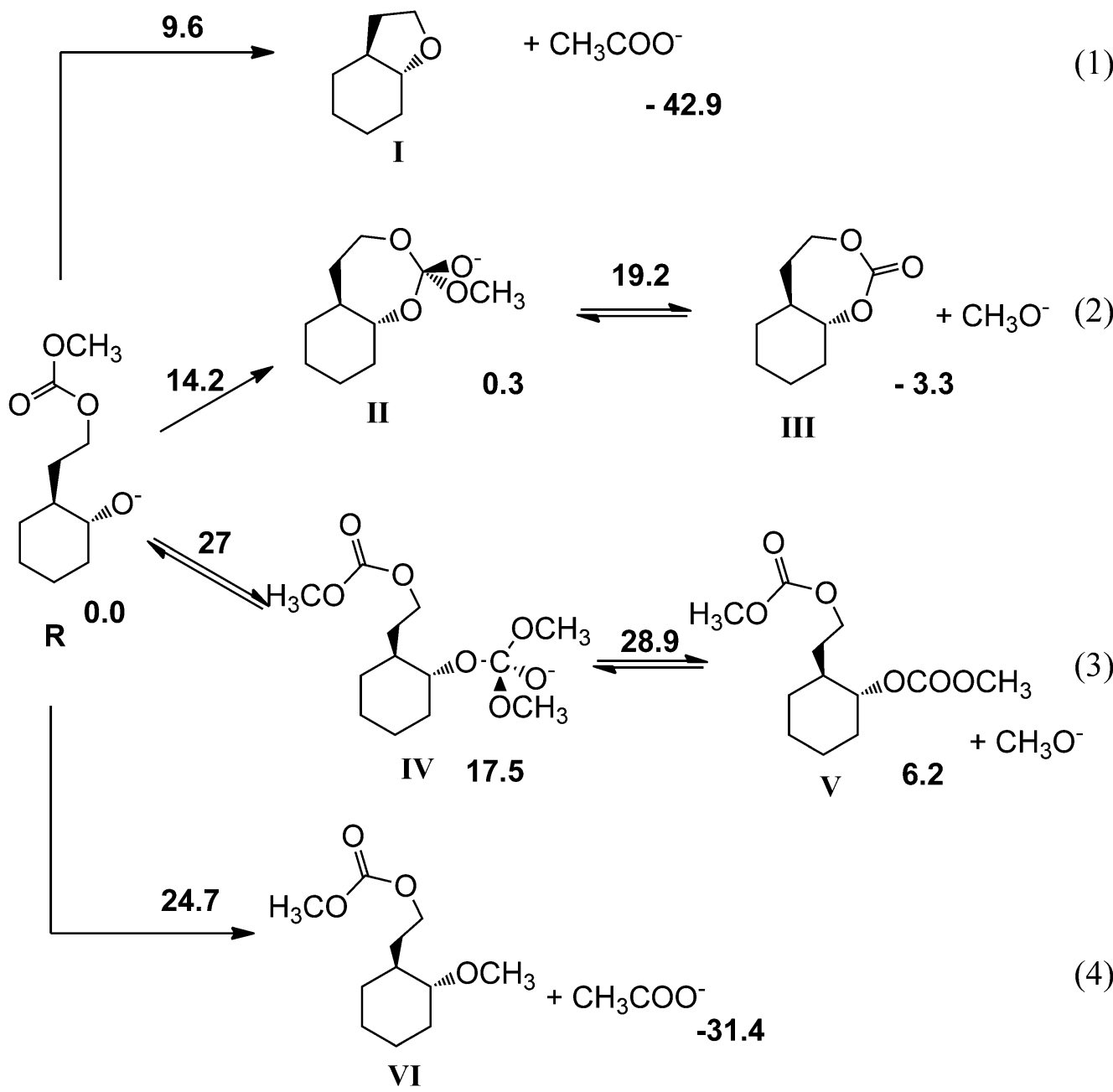

Scheme 4. Competing reaction pathways and related energy barriers. $\Delta G$ values $\left(\mathrm{kcal} \mathrm{mol}^{-1}\right)$ at $388 \mathrm{~K}$ in DMC are given. All energy values refer to the model compound (R).

barrier associated with the methylation reaction is rather high (see the Supporting Information, Table 1). Conversely, the methoxycarbonylation of the substrate (Scheme 4, pathway 3) leads to a high-energy tetrahedral intermediate (IV) through a high free energy barrier. The subsequent elimination of a methoxyl group to form $V$ has a modest free energy barrier, whereas the dissociation limit is slightly above the reactants. Because of its initial high free energy barrier (Figure 2, transition structure R-IV), this pathway has not been further considered.

Conversely, cyclization reactions require a lower free energy barrier. In particular, the energy barrier leading to I $\left(S_{N} 2\right)$ is quite low and the reaction is very exoergic. The other possible cyclization reaction $\left(S_{N} A c\right)$ forms a tetrahedral intermediate II, almost isoergic with the reactant. However, this pathway is energetically more demanding overall. Moreover, the formation of the seven-membered ring (II) is an equilibrium and the reverse-reaction transition state (Figure 2, TS II-R) has a lower energy than that leading to III (Figure 2, TS II-III).

By comparing the four relevant transition structures (TS R-VI, TS R-IV, TS R-I, and TS R-II), it was possible to investigate which effect contributed most to barrier heights. Considering only potential energy (see the Supporting Information), TS R-IV (me-

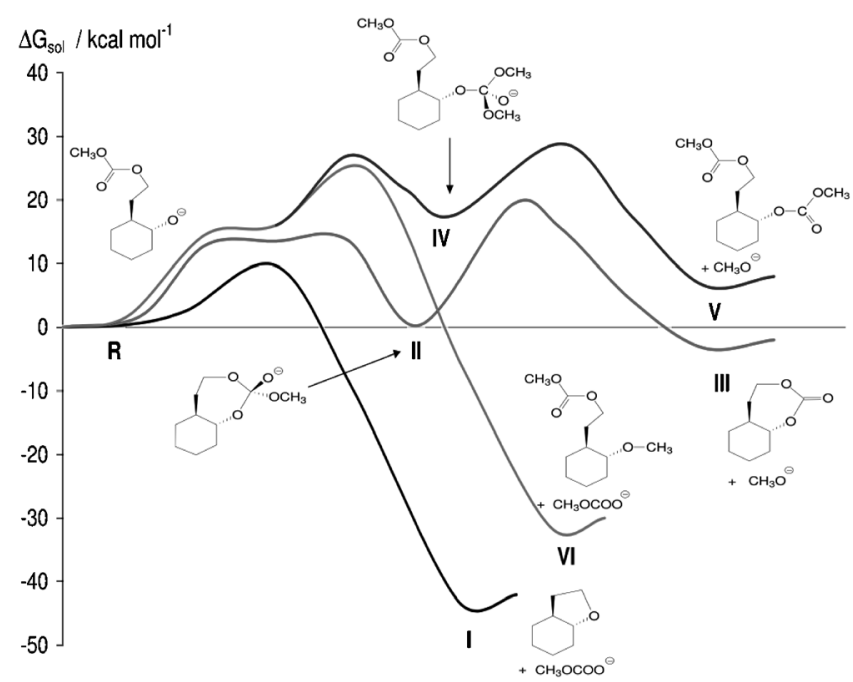

Figure 2. Free energy profile in DMC at $388 \mathrm{~K}$. 
thoxycarbonylation) would have the lowest barrier. However, in solution TS R-IV had the highest free energy barrier. This was due to the combination of two factors: entropic effects and solvation. Thus, TS R-IV was characterized by a large entropy decrease $\left(\Delta S^{\neq}=-44.2 \mathrm{cal} \mathrm{mol}^{-1} \mathrm{~K}^{-1}\right)$ because it was a bimolecular reaction, and as result, the free energy barrier in the gas phase rose significantly with respect to potential energy. Moreover, free solvation energy was also unfavorable (see the Supporting Information, Table 1). In the gas phase, according to the HSAB theory, TS R-IV would have a lower energy barrier (hard-hard interaction) than TS R-VI (hard-soft interaction). However, because entropy and solvation effects dominate the free energy barrier of TS R-IV, in solution it became higher than that of TS R-VI. Cyclization reactions showed similar solvation effects, but the activation entropy for TS R-I was only $-2.1 \mathrm{calmol}^{-1} \mathrm{~K}^{-1}$. It was higher for TS R-II $\left(\Delta S^{\neq}=-13.1 \mathrm{cal}\right.$ $\mathrm{mol}^{-1} \mathrm{~K}^{-1}$ ) probably due to a higher ring strain in the sevenmembered ring and the release of the methoxycarbonyl moiety.

The entropic effect was thus the main factor responsible for the lower barrier of TS R-I, whereas the solvation effect accentuated barrier differences. Temperature effects were also taken into account by performing free energy calculations at a higher temperature $(458 \mathrm{~K})$. However, only small changes in relative energies (at most $2 \mathrm{kcalmol}^{-1}$ ) were observed, and they did not affect the mechanistic picture discussed above (see the Supporting Information).

\section{Conclusions}

The reaction of 1,4-diols with DMC in the presence of a base and under mild conditions led to the corresponding cyclic ethers in high yields and short reaction times. It was possible to synthesize distinctive cyclic ethers and industrially relevant compounds such as (-)-norlabdane oxide and isosorbide from their related 1,4-diols in quantitative yield.

Relative to a chlorine-based procedure the DMC-mediated pathway is quantitative, occurs in one step, does not require any chlorine-based chemicals or strong acids, and does not produce any chlorinated waste material. The synthesis proposed herein is of general application, because it is effective for aliphatic and aromatic diols incorporating several functionalities (primary, secondary, tertiary, allylic, phenolic). However, this procedure requires that at least one primary alcohol group be present in the starting diol for the cyclization to take place. Most importantly, this synthesis maintains the chiral integrity of the substrate.

A computational investigation confirmed that cyclization to form the five-membered ring is the preferred pathway over seven-membered-ring closure and, even more sharply, over two different alcoholate attacks on DMC. Indeed, the fact that the last two reactions are unfavorable can be traced back to a larger entropy reduction that occurs at the relevant transition states. Then, solvent effects enhance the differences among energy barriers in the gas phase. Conversely, temperature has only a small effect on free energy barriers.
The synthetic pathway reported herein represents a good step towards a "no-chlorine-in-the making" one-pot environment-friendly method of synthesizing heterocyclic compounds. To discover the best modus operandi and achieve an industrially appealing procedure these cyclization reactions are currently under investigation in a continuous flow apparatus.

\section{Experimental Section}

General: Thin layer chromatography (TLC) was performed on precoated TLC plates (silica gel $60 \mathrm{GF} 254,0.25 \mathrm{~mm}$ ). Flash column chromatography was performed on silica gel (grade 9385, $60 \AA$ 230-400 mesh). GC-MS analyses were performed on a gas chromatograph (Agilent Technologies) equipped with a HP-5MS fused silica column $(30 \mathrm{~m} \times 0.25 \mathrm{~mm})$ and a Network mass-selective detector. All reactions were performed using DMC dried over molecular sieves ( $4 \AA$ ). All bases and catalysts were used as received without further purification.

\section{Synthetic procedures}

THF (example from Table 1, entry 1 ): In a round-bottomed flask equipped with a dephlegmator, a mixture of 1,4-butanediol $(2.0 \mathrm{~g}$, $22.2 \mathrm{mmol}, 1$ equiv), DMC ( $40 \mathrm{~g}, 44.4 \mathrm{mmol}, 2$ equiv), and $\mathrm{NaOMe}$ $(1.8 \mathrm{~g}, 33.3 \mathrm{mmol}, 1.5$ equiv) were heated at reflux while stirring continuously under a nitrogen atmosphere. The reaction was followed by NMR spectroscopy and GC-MS analysis until complete disappearance of the starting material. According to GS-MS analysis and NMR spectroscopy THF was formed in $12 \%$ yield. The solution was then filtered and the solvent removed by evaporation to isolate 1,4-di(methoxycarbonyloxy)butane $(3.40 \mathrm{~g})$ as a colorless crystalline solid in $75 \%$ yield.

1,4-Di(methoxycarbonyloxy)butane: M.p.: $\quad 61-62.3^{\circ} \mathrm{C}$; $\quad{ }^{1} \mathrm{H}$ NMR $\left(300 \mathrm{MHz}, \mathrm{CDCl}_{3}\right): \delta=4.12-4.20(\mathrm{~m}, 4 \mathrm{H}), 3.81(\mathrm{~s}, 6 \mathrm{H}), 1.74-$ $1.82 \mathrm{ppm}(\mathrm{m}, 4 \mathrm{H}) ;{ }^{13} \mathrm{C}$ NMR $\left(75 \mathrm{MHz}, \mathrm{CDCl}_{3}\right): \delta=155.6,67.2,54.6$, $25.0 \mathrm{ppm}$; HRMS: $\mathrm{m} / \mathrm{z}$ calcd for $\mathrm{C}_{8} \mathrm{H}_{14} \mathrm{O}_{6}+\mathrm{Na}^{+}: 229.0683\left[\mathrm{M}+\mathrm{Na}^{+}\right]$; found: 229.0685.2-Methyl tetrahydrofuran (example from Table 2, entry 1): In a round-bottomed flask equipped with a dephlegmator, a mixture of 1,4-pentadiol $(1.0 \mathrm{~g}, 9.6 \mathrm{mmol}, 1$ equiv), DMC (17.3 g, $192 \mathrm{mmol}, 20$ equiv), and $\mathrm{NaOMe}(0.77 \mathrm{~g}, 14.4 \mathrm{mmol}$, 1.5 equiv) were heated at reflux while stirring continuously under a nitrogen atmosphere. The reaction was followed by NMR spectroscopy and GC-MS analysis until equilibrium was reached $(2 \mathrm{~h})$. The solution was then filtered and the solvent removed by evaporation. Column chromatography using $\mathrm{CH}_{2} \mathrm{Cl}_{2} /$ methanol (95:5) as eluent allowed the isolation of 1,4-di(methoxycarbonyloxy)pentane as a light-colored oil in $60 \%$ yield.

1,4-Di(methoxycarbonyloxy)pentane: ' $\mathrm{H}$ NMR $\left(300 \mathrm{MHz}, \mathrm{CDCl}_{3}\right): \delta=$ 4.71-4.9 (m, 1 H), 4.28-4.14 (m, $2 \mathrm{H}), 3.8(\mathrm{~s}, 3 \mathrm{H}), 3.78(\mathrm{~s}, 3 \mathrm{H}), 1.9-1.5$ $(\mathrm{m}, 4 \mathrm{H}), 1.28 \mathrm{ppm}(\mathrm{d}, 3 \mathrm{H}) ;{ }^{13} \mathrm{C}$ NMR $\left(75 \mathrm{MHz}, \mathrm{CDCl}_{3}\right): \delta=155.6$, 155.2, 74.5, 67.5, 54.6, 54.4, 31.9, 24.5, 19.7 ppm; HRMS: $\mathrm{m} / \mathrm{z}$ calcd for $\mathrm{C}_{9} \mathrm{H}_{16} \mathrm{O}_{6}+\mathrm{Na}^{+}: 243.0845\left[\mathrm{M}+\mathrm{Na}^{+}\right]$; found: 243.0856 .

2,5-Dimethyltetrahydrofuran (example from Table 2, entry 5): In a round-bottomed flask equipped with a dephlegmator, 2,5-hexanediol (mixture of isomers) $(0.5 \mathrm{~g}, 4.2 \mathrm{mmol}, 1$ equiv), DMC $(7.5 \mathrm{~g}$, $83 \mathrm{mmol}, 20$ equiv), and $\mathrm{NaOMe}(0,34 \mathrm{~g}, 6.3 \mathrm{mmol}, 1.5$ equiv) were heated at reflux while stirring continuously under a nitrogen atmosphere. The reaction was followed by NMR spectroscopy and GC-MS analysis until equilibrium was reached $(6 \mathrm{~h})$. The solution was then filtered and the solvent removed by evaporation. Column chromatography using $\mathrm{CH}_{2} \mathrm{Cl}_{2} /$ methanol (99:1) as eluent 
allowed the isolation of 2,5-di(methoxycarbonyloxy)hexane as a light-colored oil in $64 \%$ yield.

2,5-Di(methoxycarbonyloxy)hexane (mixture of isomers): ${ }^{1} \mathrm{H}$ NMR $\left(300 \mathrm{MHz}, \mathrm{CDCl}_{3}\right): \delta=4.6-4.8(\mathrm{~m}, 2 \mathrm{H}), 3.8(\mathrm{~s}, 6 \mathrm{H}), 1.7-1.5(\mathrm{~m}, 4 \mathrm{H})$, $1.28 \mathrm{ppm}(\mathrm{d}, 6 \mathrm{H}) ;{ }^{13} \mathrm{C}$ NMR $\left(75 \mathrm{MHz}, \mathrm{CDCl}_{3}\right): \delta=155.2,74.9,75.6$, 54.4, 31.6, 31.2, 19.8, 19.7 ppm; HRMS: $\mathrm{m} / \mathrm{z}$ calcd for $\mathrm{C}_{10} \mathrm{H}_{18} \mathrm{O}_{6}+\mathrm{Na}$ : $257.1001\left[\mathrm{M}+\mathrm{Na}^{+}\right]$; found: 257.1035 .

2,5-Dihydrofuran (example from Table 2, entry 7): In a round-bottomed flask equipped with a dephlegmator, cis-but-2-ene-1,4-diol $(1.0 \mathrm{~g}, 11.3 \mathrm{mmol}, 1$ equiv), DMC ( $4.1 \mathrm{~g}, 45.45 \mathrm{mmol}, 4$ equiv), and NaOMe $(0.03 \mathrm{~g}, 0.56 \mathrm{mmol}, 0.05$ equiv) were heated at reflux while stirring continuously under a nitrogen atmosphere. The reaction was followed by NMR spectroscopy until complete disappearance of the starting materials. The solution was then filtered and the solvent removed by evaporation. Column chromatography using $\mathrm{CH}_{2} \mathrm{Cl}_{2} /$ methanol (98:2) as eluent allowed the isolation of (Z)-1-hydroxy 4-methoxycarbonyloxy-2-butene as a transparent oil in $24 \%$ yield and (Z)- 1,4-di(methoxycarbonyloxy)-2-butene as a light yellow oil in $31 \%$ yield.

(Z)-1-Hydroxy 4-methoxycarbonyloxy-2-butene: $:^{[26]}{ }^{1} \mathrm{H} \mathrm{NMR}(300 \mathrm{MHz}$, $\left.\mathrm{CDCl}_{3}\right): \delta=5.93-5.50(\mathrm{~m}, 2 \mathrm{H}), 4.67(\mathrm{~d}, 2 \mathrm{H}), 4.21(\mathrm{~d}, 2 \mathrm{H}), 3.69(\mathrm{~s}$, $3 \mathrm{H}), 2.88 \mathrm{ppm}(\mathrm{brs}, 1 \mathrm{H}, \mathrm{OH}) ;{ }^{13} \mathrm{C} \mathrm{NMR}\left(75 \mathrm{MHz}, \mathrm{CDCl}_{3}\right): \delta=156.9$, 133.9, 124.5, 63.3, 58.0, 54.7 ppm; GC-MS for $\mathrm{C}_{6} \mathrm{H}_{10} \mathrm{O}_{4}: M=$ $146.06 \mathrm{~g} \mathrm{~mol}^{-1}$.

(Z)- 1,4-di(methoxycarbonyloxy)-2-butene: $:^{[27]}{ }^{1} \mathrm{H}$ NMR $\quad(300 \mathrm{MHz}$, $\left.\mathrm{CDCl}_{3}\right): \delta=5.83(\mathrm{t}, 2 \mathrm{H}), 4.73(\mathrm{~d}, 2 \mathrm{H}), 3.81 \mathrm{ppm}(\mathrm{s}, 6 \mathrm{H}) ;{ }^{13} \mathrm{C} \mathrm{NMR}$ $\left(75 \mathrm{MHz}, \mathrm{CDCl}_{3}\right): \delta=156.7,127.8,63.0,58.0,54.7 \mathrm{ppm}$; GC-MS for $\mathrm{C}_{8} \mathrm{H}_{12} \mathrm{O}_{6}: M=204.06 \mathrm{~g} \mathrm{~mol}^{-1}$.

2,3-Dihydrobenzofuran (example from Table 3, entry 1): In a round-bottomed flask equipped with a dephlegmator, 2-(2-hydroxyethyl)phenol $(1.0 \mathrm{~g}, 7.24 \mathrm{mmol}, 1$ equiv), DMC $(6.5 \mathrm{~g}$, $72.4 \mathrm{mmol}, 10$ equiv), and $\mathrm{NaOMe}(0.19 \mathrm{~g}, 3.6 \mathrm{mmol}, 0.5$ equiv) were heated at reflux while stirring continuously under a nitrogen atmosphere. After $7 \mathrm{~h}$ the reaction was stopped, cooled at room temperature, and diethyl ether was added to the mixture. The reaction mixture was then filtered and the solvent evaporated. The solvent was distilled under vacuum to give the crude product that was then analysed by ${ }^{1} \mathrm{H}$ NMR spectroscopy to determine the product ratio. Finally, the product was purified by gradient elution chromatography on silica gel using first $\mathrm{CH}_{2} \mathrm{Cl}_{2} /$ cyclohexane (9:1) (for the isolation of the cyclic ether), and then $\mathrm{CH}_{2} \mathrm{Cl}_{2} /$ methanol (97:3) (for the isolation of the carbonate derivative) as eluents.

2,3-Dihydrobenzofuran (transparent liquid, $55 \%)$ : ${ }^{1} \mathrm{H}$ NMR $(300 \mathrm{MHz}$, $\left.\mathrm{CDCl}_{3}\right): \delta=7.20(\mathrm{~d}, 1 \mathrm{H}), 7.15(\mathrm{t}, 1 \mathrm{H}), 6.90-6.77(\mathrm{~m}, 2 \mathrm{H}), 4.6(\mathrm{t}, 2 \mathrm{H})$, $3.25 \mathrm{ppm}(\mathrm{t}, 2 \mathrm{H}) ;{ }^{13} \mathrm{C}$ NMR $\left(75 \mathrm{MHz}, \mathrm{CDCl}_{3}\right): \delta=159.9,127.8,126.7$, $124.8,120.2,70.9,29.6 \mathrm{ppm}$; GC-MS for $\mathrm{C}_{8} \mathrm{H}_{8} \mathrm{O}: M=120.06 \mathrm{~g} \mathrm{~mol}^{-1}$. 2-(2-methoxycarbonyloxy)phenol (light yellow oil, 29\%): ${ }^{[28]}$ M.p.: $68.5-68.8^{\circ} \mathrm{C}$; ${ }^{1} \mathrm{H}$ NMR $\left(300 \mathrm{MHz}, \mathrm{CDCl}_{3}\right): \delta=7.20-7.08(\mathrm{~m}, 2 \mathrm{H})$, 6.92-6.80 (m, 2H), $5.95(\mathrm{~s}, 1 \mathrm{H}, \mathrm{OH}), 4.37(\mathrm{t}, 2 \mathrm{H}), 3.81(\mathrm{~s}, 3 \mathrm{H})$, $3.05 \mathrm{ppm}(\mathrm{t}, 2 \mathrm{H}) ;{ }^{13} \mathrm{C}$ NMR $\left(75 \mathrm{MHz}, \mathrm{CDCl}_{3}\right): \delta=156.9,153.4,130.9$, $128.2,120.6,67.6,54.8,30.0 \mathrm{ppm}$; GC-MS for $\mathrm{C}_{10} \mathrm{H}_{12} \mathrm{O}_{4}: M=$ $196.07 \mathrm{~g} \mathrm{~mol}^{-1}$.

Phthalan (example from Table 3, entry 5): In a round-bottomed flask equipped with a dephlegmator, dihydroxymethylbenzene $(1.0 \mathrm{~g}, 7.24 \mathrm{mmol}, 1$ equiv), DMC (6.5 g, $72.4 \mathrm{mmol}, 10$ equiv), and NaOMe $(0.19 \mathrm{~g}, 3.6 \mathrm{mmol}, 0.5$ equiv) were heated at reflux while stirring continuously under a nitrogen atmosphere. After $7 \mathrm{~h}$ the reaction was stopped, cooled at room temperature, and diethyl ether was added to the mixture. The reaction mixture was then filtered and the solvent evaporated. The solvent was distilled under vacuum to give the crude product that was then analysed by ${ }^{1} \mathrm{H}$ NMR spectroscopy to determine the product ratio. Finally, the product was purified by gradient elution chromatography on silica gel using first $\mathrm{CH}_{2} \mathrm{Cl}_{2} /$ cyclohexane (9:1) (for the isolation of the cyclic ether), and then $\mathrm{CH}_{2} \mathrm{Cl}_{2} /$ methanol (97:3) (for the isolation of the carbonate derivative) as eluents.

Phthalan (transparent liquid, 30\%): Characterization data were consistent with those obtained for the commercially available compound.

1,2-Bis[(methoxycarbonyloxy)methyl)]benzene (light yellow liquid, $41 \%):$ M.p.: $51-51.5^{\circ} \mathrm{C} ;{ }^{1} \mathrm{H}$ NMR $\left(300 \mathrm{MHz}, \mathrm{CDCl}_{3}\right): \delta=7.48-7.30(\mathrm{~m}$ $4 \mathrm{H}), 5.27(\mathrm{~s}, 4 \mathrm{H}), 3.77 \mathrm{ppm}(\mathrm{s}, 6 \mathrm{H}) ;{ }^{13} \mathrm{C}$ NMR $\left(75 \mathrm{MHz}, \mathrm{CDCl}_{3}\right): \delta=$ $155.4,133.8,129.8,128.9,66.9,54.8 \mathrm{ppm}$; HRMS: $\mathrm{m} / \mathrm{z}$ calcd for $\mathrm{C}_{12} \mathrm{H}_{14} \mathrm{O}_{6}+\mathrm{Na}^{+}: 277.0688\left[\mathrm{M}+\mathrm{Na}^{+}\right]$; found: 277.0722 .

(-)-Norlabdane (ambroxan) (example from Table 4, entry 1): In a round-bottomed flask equipped with a dephlegmator, amberlyn diol $(1.0 \mathrm{~g}, 3.93 \mathrm{mmol}, 1$ equiv), DMC $(10.6 \mathrm{~g}, 118.0 \mathrm{mmol}$, 30 equiv), and potassium tert-butoxide $(0,88 \mathrm{~g}, 7.87 \mathrm{mmol}, 2$ equiv) were heated at reflux while stirring continuously under a nitrogen atmosphere. The reaction was followed by TLC until complete disappearance of the starting materials. The solution was then filtered and DMC removed by evaporation to afford ambroxan as a colorless crystalline powder in $95 \%$ yield. Purer samples of ambroxan could be obtained either by crystallisation from 2-propanol or by column chromatography using $\mathrm{CH}_{2} \mathrm{Cl}_{2} /$ methanol (98:2) as eluent.

(-)-Norlabdane: ${ }^{[17,22]}$ M.p.: $69.1-70{ }^{\circ} \mathrm{C} ;{ }^{1} \mathrm{H}$ NMR $\left(300 \mathrm{MHz}, \mathrm{CDCl}_{3}\right)$ : $\delta=0.84(\mathrm{~s}, 3 \mathrm{H}), 0.85(\mathrm{~s}, 3 \mathrm{H}), 0.89(\mathrm{~s}, 3 \mathrm{H}), 0.91-1.09(\mathrm{~m}, 2 \mathrm{H}), 1.12(\mathrm{~s}$, $3 \mathrm{H}), 1.36-1.51(\mathrm{~m}, 7 \mathrm{H}), 6.92-6.80(\mathrm{~m}, 2 \mathrm{H}), 5.95(\mathrm{~s}, 1 \mathrm{H}, \mathrm{OH}), 4.37(\mathrm{t}$, $2 \mathrm{H}), 3.81(\mathrm{~s}, 3 \mathrm{H}), 3.05 \mathrm{ppm}(\mathrm{t}, 2 \mathrm{H}) ;{ }^{13} \mathrm{C}$ NMR $\left(75 \mathrm{MHz}, \mathrm{CDCl}_{3}\right): \delta=$ $79.8,64.8,60.0,57.1,42.3,39.8,39.6,36.0,33.5,32.9,22.5,21.0$, 20.5, 18.3, $14.9 \mathrm{ppm}$; GC-MS for $\mathrm{C}_{16} \mathrm{H}_{28} \mathrm{O}: M=236.21 \mathrm{~g} \mathrm{~mol}^{-1}$.

Monomethoxycarbonyloxy derivative of Amberlyn diol (Table 4, entry 7):[22] The compound was purified by column chromatography $\left(\mathrm{CH}_{2} \mathrm{Cl}_{2} / \mathrm{EtOAC}, 92: 8\right)$, and was isolated as a yellow oil in $90 \%$ yield.

Isosorbide (example from Table 5, entry 4): A mixture of D-sorbitol $(2.0 \mathrm{~g}, 10.98 \mathrm{mmol}, 1$ equiv), DMC $(8 \mathrm{~g}, 87.88 \mathrm{mmol}, 8$ equiv), NaOMe $2.4 \mathrm{~g}, 43.42 \mathrm{mmol}, 4$ equiv), and methanol ( $30 \mathrm{~mL}$ ) was placed in a round-bottomed flask, and heated at reflux while stirring continuously under a nitrogen atmosphere. After $8 \mathrm{~h}$ the reaction was stopped, cooled at room temperature, and diethyl ether was added to the mixture. The reaction mixture was then filtered and the solvent evaporated. The solvent was distilled under vacuum to afford the crude product. Finally, the product was purified by gradient elution chromatography on silica gel using $\mathrm{CH}_{2} \mathrm{Cl}_{2} /$ methanol (9:1) as eluent.

Isosorbide (light yellow crystals, 75\%): Characterization data were consistent with those obtained for the commercially available compound.

\section{Ab initio calculations}

The potential energy surface (PES) was studied by DFT calculations making use of the B3LYP functional. ${ }^{[29]}$ The $6-311 \mathrm{G}(\mathrm{d})$ polarized basis set $^{[30]}$ was used in geometry optimizations. The nature of each critical point (reactant, product, intermediate, or transition structure) was determined by harmonic vibrational analysis. To obtain an estimate of energy barriers, single-point energy calculations were carried out by using Dunning's correlation-consistent basis set (aug-cc-pVTZ) ${ }^{[31]}$ Final free energy values were calculated by combining $6-311 \mathrm{G}(\mathrm{d})$ thermochemical corrections with singlepoint DFT/aug-cc-pVTZ energy values.

Solvent effects were taken into account by the self-consistent reaction field method using the integral equation formalism for the po- 
larizable continuum model (IEF-PCM). ${ }^{[32]}$ Single point IEF-PCM energy calculations were carried out at the DFT/aug-cc-pVTZ level. Chemico-physical properties were used to parameterize the solvent (DMC), which was defined as "nonstandard" in the Gaussian 03 program, by which all calculations were carried out. ${ }^{[33]}$

\section{Acknowledgements}

We acknowledge Imperial Chemical Industries Ltd. (ICI) for the support and funding of a part of this work.

Keywords: ab initio calculations - cyclization - green chemistry · spectroscopy · synthetic methods

[1] a) S. V. Bhat, B. S. Bajwa, H. Dornauer, N. J. de Souza, H.-W. Fehlhaber, Tetrahedron Lett. 1977, 18, 1669-1672; b) S. V. Bhat, B. S. Bajwa, H. Dornauer, N. J. de Souza, J. Chem. Soc. Perkin Trans. 1 1982, 767-771.

[2] S. V. Bhat, Prog. Chem. Org. Nat. Prod. 1993, 1.

[3] J.W. Westley, Polyethers Antibiotics: Naturally Occurring Acid lonophores, Vol. 1-2, Marcel Dekker, New York, 1982.

[4] a) M. Imoto, K. Umezawa, Y. Takahashi, H. Naganawa, Y. litaka, H. Nakamura, Y. Koizurni, Y. Sasaki, M. Hamada, T. Sawa, T. Takeuchi, J. Nat. Prod. 1990, 53, 825-829; b) H. Odai, K. Shindo, A. Odagawa, J. Mochizuki, M. Hamada, T. Takeuchi, J. Antibiot. 1994, 47, 939-941; c) N. O. Fuller, J. P. Morken, Org. Lett. 2005, 7, 4867-4869.

[5] G. Wang, F. J. Burczynski, B. B. Hasinoff, K. Zhang, Q. Lu, J. E. Anderson, Mol. Pharmaceut. 2009, 6, 895-904.

[6] J. K. Rossiter, Chem. Rev. 1996, 96, 3201-3240.

[7] a) E. K. Lee, Y. H. Baek, Patent EP1939190, 2008, to Hysung corporation b) I. I. Geiman, L. F. Bulenkova, A. A. Lazdin'sh, A. K. Veinberg, V. A. Slavinskaya, A. A. Avots, Chem. Heterocycl. Compd. 1981, 17, 314-316; c) T. Shibata, R. Fujiwara, Y. Ueno, Synlett 2005, 152-154; d) G. V. Sharma, K. R. Kumar, P. Sreenivas, P. R. Krishna, M. S. Chorghade, Tetrahedron: Asymmetry 2002, 13, 687-690; e) R. I. Khusnutdinov, N. A. Shchadneva A. R. Baiguzina, Y. Lavrentieva, U. M. Dzhemilev, Russ. Chem. Bull. 2002 51, 2074-2079; f) B. Panda, T. K. Sarkar, Tetrahedron Lett. 2008, 49, $6701-6703$; g) H. Zhao, J. E. Holladay, H. Brown, Z. C. Zhang, Science 2007, 316, 1597-1600.

[8] a) O. Lindner, L. Rodefeld, Benzenesulfonic Acids and Their Derivatives, in Ullmann's Encyclopedia of Industrial Chemistry, Wiley-VCH, Weinheim, 2001; b) C. S. Salteris, I. D. Kostas, M. Micha-Screttas, G. A. Heropoulos, C. G. Screttas, A. Terzis, J. Org. Chem. 1999, 64, 5589-5592; c) F. Ojima, T. Matsue, T. Osa, Chem. Lett. 1987, 2235-2238; d) C. Ferreri, C. Costantino, C. Chatgilialoglu, R. Boukherroub, G. Manuel, J. Organomet. Chem. 1998, 554, 135-138; e) G. Tagliavini, D. Marton, D. Furlani, Tetrahedron 1989, 45, 1187-1196; f) L. Djakovitch, J. Eames, R. V. H. Jones, S. McIntyre, S. Warren, Tetrahedron Lett. 1995, 36, 1723-1726; g) E. Adaligil, B. D. Davis, D. G. Hilmey, Y. Shen, J. M. Spruell, J. S. Brodbelt, K. N. Houk L. A. Paquette, J. Org. Chem. 2007, 72, 6215-6223; h) L. M. Grubb, B. P. Branchaud, J. Org. Chem. 1997, 62, 242-243; i) K. Matsuo, T. Arase, S Ishida, Y. Sakaguchi, Heterocycles 1996, 43, 1287-1300; j) J. Moulines, A.-M. Lamidey, V. Desvergnes-Breuil, Synth. Commun. 2001, 31, 749758; k) T. Koga, Y. Aoki, T. Hirose, H. Nohira, Tetrahedron: Asymmetry 1998, 9, 3819-3824.

[9] a) Comprehensive Organic Synthesis: Selectivity, Strategy and Efficiency in Modern Organic Chemistry, Vol. 6 (Eds.: B. Trost, I. Fleming), Pergamon, London, 1992, 22-31; b) K. P. Herlihy, D. S. Sagatys, J. Chem. Res. 1996, 2, 501-524; c) J. P. Vozza, J. Org. Chem. 1959, 24, 720; d) P. Kraft, patent WO2008/148236, 2008, to Givaudan Sa; e) A. Molnár, K. Felfoeldi, M. Bartok, Tetrahedron 1981, 37, 2149-2152; f) K. K. Showa Denko US patent 6372921, 2002; g) N. Meyer, D. Seebach, Chem. Berich. 1980, 113, 1304-1319; h) J. E. Holladay, J. Hu, X. Zhang, Y. Wang, patent US2007/ 173654 2007; i) W. C. Brinegar, M. Wohlers, M. A. Hubbard, E. G. Zey, G. Kvakovszky, T. H. Shockley, R. Roesky, U. Dingerdissen, W. Kind, patent US6639067 2003; j) J. Defaye, A. Gadelle, C. Pedersen, Carbohydr. Res. 1990, 205, $191-202$.
[10] a) A. Costa, J. M. Riego, Synth. Commun. 1987, 17, 1373-1376; b) M. B. Smith, J. March, Adv. Org. Chem. 2001, 479-480; c) T. Zheng, R. S. Narayan, J. M. Schomaker, B. Borhan, J. Am. Chem. Soc. 2005, 127, 69466947; d) M. Aquino, S. Cardani, G. Fronza, C. Fuganti, P. R. Fernandez, A. Tagliani, Tetrahedron 1991, 47, 7887-7896; e) A. C. Spivey, A. Maddaford, T. Fekner, A. J. Redgrave, C. S. Frampton, J. Chem. Soc. Perkin Trans. 1 2000, 3460-3468.

[11] a) H. Qian, X. Han, R. A. Widenhoefer, J. Am. Chem. Soc. 2004, 126, 9536-9537; b) Z. Zhang, C. Liu, R. E. Kinder, X. Han, H. Qian, R. A. Widenhoefer, J. Am. Chem. Soc. 2006, 128, 9066-9073; c) Y.-C. Lee, T.-C. Young, Synthesis 2006, 3621-3624; d) Y. Fang, C. Li, J. Am. Chem. Soc. 2007, 129, 8092-8093; e) M. Yus, T. Soler, F. Foubelo, Tetrahedron 2002, $58,7009-7016$.

[12] E. J. Alvarez-Manzaneda, R. Chaboun, E. Alvarez, E. Cabrera, R. AlvarezManzaneda, A. Haidour, J. M. Ramos, Synlett 2006, 1829-1834.

[13] Asahi Kasei Chemicals Corporation Patent, WO2007/34669A1, 2007.

[14] a) P. Tundo, A. Perosa, F. Zecchini, Methods and Reagents for Green Chemistry,Wiley, NJ, USA, 2007; b) P. Tundo, M. Selva, A. Perosa, S. Memoli, J. Org. Chem. 2002, 67, 1071; c) A. E. Rosamilia, F. Aricò, P. Tundo, J. Org. Chem. 2008, 73, 1559-1562; d) P. Tundo, S. Memoli, D. Hérault, K. Hill, Green Chem. 2004, 6, 609-612; e) P. Tundo, F. Aricò A. E. Rosamilia, S. Memoli, Green Chem. 2008, 10, 1182; f) P. Tundo, F. Aricò, A. E. Rosamilia, M. Rigo, A. Maranzana, G. Tonachini, Pure Appl. Chem. 2009, 81, 1971-1979.

[15] L. Cotarca, H. Ecket, Phosgenations-A Handbook, Wiley-VCH, 2003.

[16] M. Selva, C. A. Marques, P. Tundo, J. Chem. Soc. Perkin Trans. 1 1994, $1323-1328$.

[17] a) H. S. Bevinakatti, C. P. Newman, S. Ellwood, P. Tundo, F. Aricò, WO2009010791 (A2), 2009; b) F. Aricò, U. Toniolo, P. Tundo, Green Chem. 2011, accepted (DOI:10.1039/C1GC15698E).

[18] H. B. Mereyala, S. K. Mamidyala, Tetrahedron Lett. 2004, 45, 2965-2966.

[19] Preliminary experiments showed that a solution of 1,4-butanediol and DMC (1:5 molar ratio) in methanol is readily and quantitatively converted into THF at $180^{\circ} \mathrm{C}$ under continuous flow conditions (using potassium carbonate and polyethyleneglycol 2500 supported on $\alpha$-alumina beads as the catalyst); this procedure (gas-liquid phase-transfer catalysis) is similar to the one recently reported in P. Tundo, A. E. Rosamilia, F. Aricò, J. Chem. Educ. 2010, 87, 1233-1235.

[20] R. A. Giacomini, P. C. M. Miranda L. H. B. Baptistella, P. M. Imamura, ARKIVOK 2003, $x, 314-332$.

[21] a) P. N. Davey, L. Payne, L. Sidney; C. Tse, US Patent 5821375, 1998; b) D. H. R. Barton, S. I. Parekh, D. K. Taylor, C. Tse, US Patent 5463089 , 1994; c) G. Knuebel, A. Bomhard, T. Markert, US patent 5811560, 1998.

[22] A sample of pure Amberyl diol was provided by QUEST (Imperial Chemical Industries $\mathrm{ICl}$ ).

[23] G. Flèche, M. Huchette, Starch/Staerke 1986, 38, 26-30.

[24] P. Tundo, F. Aricò, G. Gauthier, L. Rossi, A. E. Rosamilia, H. Bevinakatti, R. L. Sievert, C. P. Newman, ChemSusChem 2010, 3, 566-570.

[25] a) R. G. Pearson, J. Am. Chem. Soc. 1963, 85, 3533-3539; b) R. G. Pearson, J. Songstad, J. Am. Chem. Soc. 1967, 89, 1827-1836.

[26] a) W. Oppolzer, A. Fürstner, Helv. Chim. Acta 1993, 76, 2329-2337; b) P. Grzywacz, S. Marczak, J. Wicha, J. Org. Chem. 1997, 62, 5293-5298.

[27] a) T. Hayashi, A. Yamamoto, Y. Ito, Tetrahedron Lett. 1988, 29, 669-672; b) T. Hayashi, A. Ohno, S.-J. Lu, Y. Matsumoto, E. Fukuyo, K. Yanagi, J. Am. Chem. Soc. 1994, 116, 4221-4226; c) T. Hayashi, M. Yamane, A. Ohno, J. Org. Chem. 1997, 62, 204-207.

[28] R. Bernini, E. Mincione, F. Crisante, M. Barontini, G. Fabrizi, P. Gentili, Tetrahedron Lett. 2007, 48, 7000-7003.

[29] a) A. D. Becke, Phys. Rev. A 1988, 38, 3098-3100; b) A. D. Becke, ACS Symp. Ser. 1989, 394, 165; c) A. D. Becke, J. Chem. Phys. 1993, 98, 56485652; d) C. Lee, W. Yang, R. G. Parr, Phys. Rev. B 1988, 37, 785-789.

[30] a) W. J. Hehre, R. Ditchfield, J. A. Pople, J. Chem. Phys. 1972, 56, 22572261 ; b) P. C. Hariharan, J. A. Pople, Theor. Chim. Acta 1973, 28, $213-$ 222 ; c) T. Clark, J. Chandrasekhar, P. V. R. Schleyer, J. Comput. Chem. 1983, 4, 294-301; d) M. J. Frisch, J. A. Pople, J. S. Binkley, J. Chem. Phys. $1984,80,3265-3269$.

[31] a) T. H. Dunning, J. Chem. Phys. 1989, 90, 1007-1024; b) R. A. Kendall, T. H. Dunning, R. J. Harrison, J. Chem. Phys. 1992, 96, 6796-6807.

[32] M. Cossi, V. Barone, B. Mennucci, J. Tomasi, Chem. Phys. Lett. 1998, 286, $253-260$. 
[33] Gaussian 03, Revision D.02, M. J. Frisch, G. W. Trucks, H. B. Schlegel, G. E. Scuseria, M. A. Robb, J. R. Cheeseman, J. A. Montgomery, Jr., T. Vreven, K. N. Kudin, J. C. Burant, J. M. Millam, S. S. lyengar, J. Tomasi, V. Barone, B. Mennucci, M. Cossi, G. Scalmani, N. Rega, G. A. Petersson, H. Nakatsuji, M. Hada, M. Ehara, K. Toyota, R. Fukuda, J. Hasegawa, M. Ishida, T. Nakajima, Y. Honda, O. Kitao, H. Nakai, M. Klene, X. Li, J. E. Knox, H. P. Hratchian, J. B. Cross, V. Bakken, C. Adamo, J. Jaramillo, R. Gomperts, R. E. Stratmann, O. Yazyev, A. J. Austin, R. Cammi, C. Pomelli, J. W. Ochterski, P. Y. Ayala, K. Morokuma, G. A. Voth, P. Salvador, J. J. Dannenberg, V. G. Zakrzewski, S. Dapprich, A. D. Daniels, M. C. Strain, O. Farkas, D. K.
Malick, A. D. Rabuck, K. Raghavachari, J. B. Foresman, J. V. Ortiz, Q. Cui, A. G. Baboul, S. Clifford, J. Cioslowski, B. B. Stefanov, G. Liu, A. Liashenko, P. Piskorz, I. Komaromi, R. L. Martin, D. J. Fox, T. Keith, M. A. Al-Laham, C. Y. Peng, A. Nanayakkara, M. Challacombe, P. M. W. Gill, B. Johnson, W. Chen, M. W. Wong, C. Gonzalez, and J. A. Pople, Gaussian, Inc., Wallingford CT, 2004.

Received: November 23, 2011

Published online on June 22, 2012 